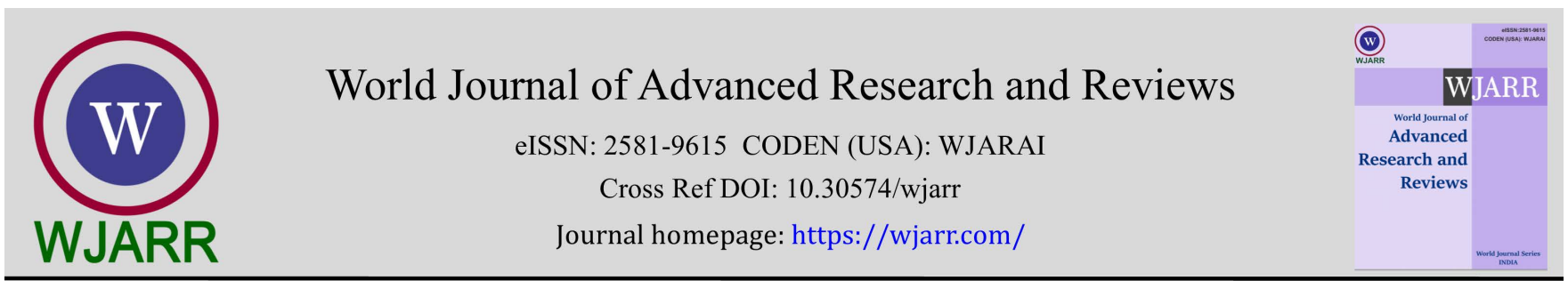

(RESEARCh ARTICLE)

Check for updates

\title{
Improvement in bituminous surface course using waste plastic in acid-rain susceptible area's
}

\author{
Shabnum Masood 1* , Er. Ajay Kumar Duggal 2, Er. Shabina Masoodi ${ }^{1}$, Er. Irtiza Khurshid ${ }^{1}$ and Er. Gulam - \\ Mohi-ud-din Rather ${ }^{1}$ \\ ${ }^{1}$ Department of Civil Engineering, SSM College of Engineering, Kashmir, India. \\ 2 Department of Civil Engineering, National Institute of Technical Teachers Training \& Research, Chandigarh, India.
}

World Journal of Advanced Research and Reviews, 2021, 11(03), 405-412

Publication history: Received on 22 August 2021; revised on 26 September 2021; accepted on 28 September 2021

Article DOI: https://doi.org/10.30574/wjarr.2021.11.3.0479

\begin{abstract}
Acid rain as an important environmental issue has negative impact on bitumen performance, thereby shortening the service life of bituminous pavements. Rapid industrial and economic developments causes negative changes in the environment, including acid rain. Acid rain consisting of sulphuric acid and nitric acid has adverse effects on bituminous pavements. Both these acids react with the bitumen and adversely effect's the properties of the bitumen leading to degradation of pavements at early stage of life. Early degradation of such pavements can be reduced to some extent by using waste plastic in bituminous surface course. Besides acid rain puts an adverse effect on the properties of bitumen, it also percolates deep down in the various down layers of pavements and reduces the serviceability of our pavements \& its foundation. Waste plastic such as PET water bottles cannot only prevents the early degradation of pavements but also can prevents entry of acid rain into deep down layers of pavement as it absorbs acid rain water which makes it hydroscopic as because of it acid rain water does not percolate deep down into below pavement layers. In this paper, interaction between constituents of acid rain and bitumen is being investigated by analyzing the effect of sulphuric acid and nitric acid on control mix (mix without plastic content) \& 6\% WPET mix (mix with 6\% waste plastic PET content) by using Marshal stability test. Also, it's evaluated how improvement in bituminous surface course can be done by using waste plastic on acid rain area's so that our pavements show good safety \& serviceability.
\end{abstract}

Keywords: Environment; Acid Rain; Bitumen; waste plastic; Marshal Stability test.

\section{Introduction}

Acid rain or acid deposition, is a broad term that includes any form of precipitation with acidic components such as sulphuric or nitric acid that falls to the ground from atmosphere in wet or dry forms. This can include rain, snow, fog, hail or even dust that is acidic. Wet deposition is what we most commonly think of as acid rain. Normally rain water is slightly acidic with a PH range of 5.3-6.0 because carbon dioxide and water present in the air together to form carbonic acid which is weak acid. When the PH level of rain water falls below this range, it becomes acidic rain. Presently large amount deposition is witnessed in the south-eastern Canada, north-eastern United States and most of the Europe including portions of Sweden, Norway and Germany. In addition, some amount of acid deposition in found in parts of south Asia, Sri Lanka and India. Forms of Acid Rain

There are two forms in which acid deposition occurs

Wet and dry. Both are discussed below:

\footnotetext{
${ }^{*}$ Corresponding author: Shabnum Masood ; E-mail: ershubu121@gmail.com

Department of Civil Engineering, SSM College of Engineering, Kashmir, India

Copyright (C) 2021 Author(s) retain the copyright of this article. This article is published under the terms of the Creative Commons Attribution Liscense 4.0.
} 


\subsection{Wet Deposition}

When the wind blows the acidic chemicals in the air to the areas where the weather is wet, the acids fall to the ground in the form of rain, sleet, fog, snow or mist. It removes acid from the atmosphere and deposits them on the earth's surface. When this acid flows through the ground, it affects a large number of plants, animals and aquatic life. The water from drain flows into rivers and canals which is them mixed up with seawater, thereby affecting marine habitats. Also it has adverse effect on the quality of pavements, reducing the structural integrity of our pavements by means of pothole formations, spine outs \& crashes.

\subsection{1. . Dry Deposition}

If the wind blows the acidic chemicals in the air to the areas where the weather is dry, the acidic pollutants slip into dust or smoke and fall to the ground as dry particles. These stick to the ground and other surfaces such as cars, houses, trees and buildings. Almost 50\% of the acidic pollutants in the atmosphere fall back through dry deposition. These acidic pollutants can be washed away from the earth surface by rainstorms.

It was discovered way back in the 1800s during the Industrial Revolution. A Scottish chemist, Robert Angus Smith, was first to discover this phenomenon in 1852 as a relationship between acid rain and atmospheric pollution in Manchester, England. But it gained public attention mainly in the 1960s. The term was coined in 1972 when the NY Times published reports about the climate change effects which started arising due to the occurrence of acid rain in the Hubbard Brook Experimental Forest in New Hampshire.

\subsubsection{Causes of Acid Rain}

Both natural and man-made sources are known to play a role in the formation of acid rain. But, it is mainly caused by the combustion of fossil fuels which results in emissions of sulphur dioxide (SO2) and nitrogen oxides (NOx).

\subsection{Natural Sources}

The major natural causal agent for acid rain is volcanic emissions. Volcanoes emit acid-producing gases to create higher than normal amounts of acid rain or any other form of precipitation such as fog and snow to an extent of affecting vegetation cover and health of residents within the surrounding. Decaying vegetation, wildfires and biological processes within the environment also generate acid rain forming gases. Dimethyl sulphide is a typical example of a major biological contributor to sulphur-containing elements into the atmosphere. Lightning strikes also naturally produce nitric oxides that react with water molecules via electrical activity to produce nitric acid, thereby forming acid rain.

\subsection{Man-made Sources}

Human activities leading to chemical gas emissions such as sulphur and nitrogen are the primary contributors to acid rain. The activities include air pollution sources emitting sulphur and nitrogen gases like factories, power generation facilities, and automobiles. In particular, the use of coal for electrical power generation is the biggest contributor to gaseous emissions leading to acid rain. Automobiles and factories also release high scores of gaseous emissions on a daily basis into the air, especially in highly industrialized areas and urban regions with large numbers of car traffic.

\section{Methodology}

\subsection{Materials used}

- Aggregates

- bitumen

- Cement

- Waste PET bottles

Aggregates, cement \& waste PET bottles were used for making various samples for marshal stability test. Three samples each of control mix (mix with bitumen, aggregates \& cement only) and 6\% WPET mix (mix with bitumen, aggregates, cement, \& 6\% waste PET bottles by total weight of marshal sample that is $1200 \mathrm{gm}$ ). In $6 \%$ WPET mix, weight of aggregates was replaced by weight of waste plastic. One from each, were subjected to 3 hours acid immersion, 5 hours acid immersion and maximum 10 hours acid immersion. After that marshal stability test was performed on all the three ranges of different timing. 


\subsection{Tests performed}

\subsubsection{Marshal stability test}

Marshall Stability Test is used for finding the Stability Of bituminous mixes. Marshall Stability Test implements the Principle that the Stability of the bituminous mix is its resistance to flow when loaded on lateral surfaces. In general, it may be defined as the capacity of load which the mixes can carry at $60^{\circ} \mathrm{c}$. The measuring unit of Stability is kg.

Flexibility of mixes can be determined by using Flow value. It is measured as deformation in 0.25 units from the application of load to the point when the load is maximum.

\subsection{Procedure followed}

First selection of proportions of coarse aggregate and filler is done in order to meet the requirements as per IRC. The weight of mix should be kept as $1200 \mathrm{~g}$.

The aggregates are heated to $170^{\circ} \mathrm{C}$ and bitumen is heated to $163^{\circ} \mathrm{C}$ respectively.

Mix the materials and transfer the material to the compaction mould arranged on the compaction pedestal.

75 Blows are given on both sides of the sample specimen with a standard hammer $(4.86 \mathrm{~kg}, 45 \mathrm{~cm}-\mathrm{free}$ fall).

Keep the specimen in the mould for few minutes for cooling

Remove the specimen by gently pushing it from the mould.

The specimen is marked and cured at room temperature.

A number of specimens are prepared by same method with 6\% WPET content And control mix

Both the specimens control mix \& 6\% WPET mix were subjected to acid immersion (sulphuric acid + nitric acid) for 3 hours, 5 hours \& maximum 10 hours.

Test the sample by applying the load on the specimen at the rate of $5 \mathrm{~cm} / \mathrm{min}$. Check the Stability and Flow Value of the samples after 3 hours, 5 hours and 10 hours of acid immersion

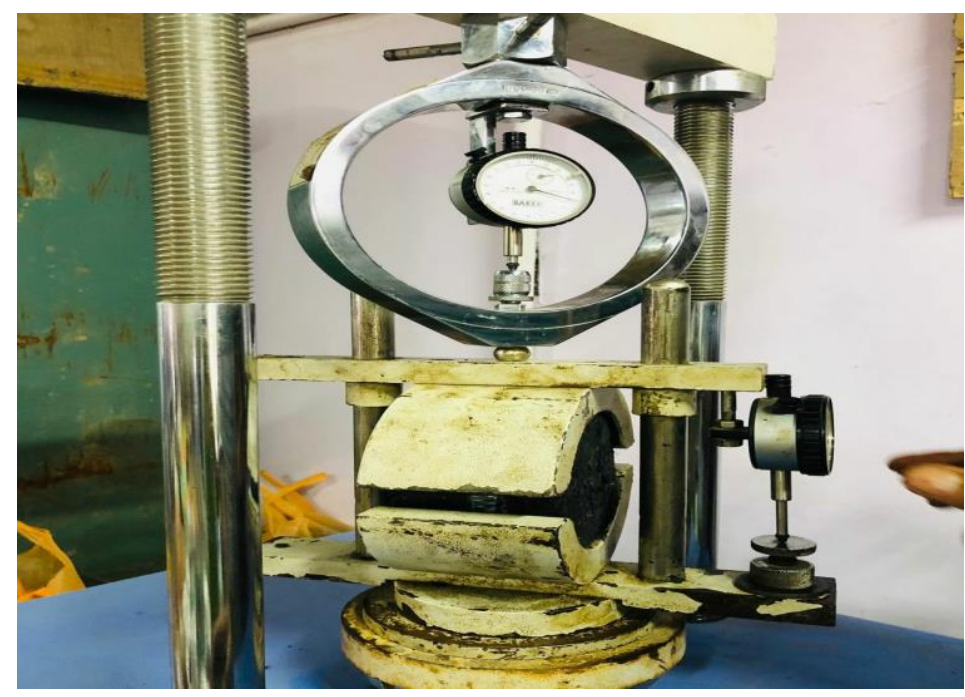

Figure 1 Marshal stability test 


\section{Results}

Both control mix \& 6\% WPET mix were immersed in acid solution of sulphuric acid and nitric acid for about 3 hours. After 3 hours of immersion, both the samples were subjected to marshal stability test \& various properties of these samples were evaluated. 6\% WPET mix when compared to control mix after 3 hours of acid immersion shows more strength. In the same way after 5 hours \& 07 hours of acid immersion, both the samples were subjected to marshal stability test \& various properties of both mixes were evaluated.

Table 1 test results after 3 hours of acid immersion

\begin{tabular}{|l|l|l|}
\hline $\begin{array}{l}\text { Bitumen Content } \\
\text { ( 03 hours ) }\end{array}$ & Control mix & PET 6\% \\
\hline Specific Gravity of Bitumen & 1.0 & 1.0 \\
\hline Density (g/cc) & 2.34 & 2.285 \\
\hline Specific Gravity of Aggregate Blend & 2.65 & 2.41 \\
\hline Volume of Bitumen, Vb(\%) & 13.170 & 12.933 \\
\hline Volume of Aggregate, Va(\%) & 81.91 & 84.30 \\
\hline $\begin{array}{l}\text { Voids in Mineral Aggregate, VMA } \\
\text { (\%) }\end{array}$ & 17.1 & 14.6 \\
\hline Voids Filled with Bitumen, VFB (\%) & 69.7 & 80.3 \\
\hline Air Voids, \% & 5.1 & 3.61 \\
\hline Stability, kg & 1234 & 1907 \\
\hline Flow Value, mm & 2.61 & 3.3 \\
\hline
\end{tabular}

Table 2 test results after 5 hours of acid immersion

\begin{tabular}{|l|l|l|}
\hline Bitumen Content & Control mix & PET 6\% \\
\hline ( 5 hours ) & & \\
\hline Specific Gravity of Bitumen & 1.0 & 1.0 \\
\hline Density (g/cc) & 2.327 & 2.285 \\
\hline Specific Gravity of Aggregate Blend & 2.68 & 2.557 \\
\hline Volume of Bitumen, Vb(\%) & 13.170 & 12.933 \\
\hline Volume of Aggregate, $\mathrm{Va}_{\mathrm{a}} \%$ ) & 81.91 & 84.30 \\
\hline $\begin{array}{l}\text { Voids in Mineral Aggregate, VMA } \\
\text { (\%) }\end{array}$ & 19.09 & 14.7 \\
\hline Voids Filled with Bitumen, VFB (\%) & 72.65 & 83.37 \\
\hline Air Voids, \% & 4.07 & 2.19 \\
\hline Stability, kg & 985 & 1708 \\
\hline Flow value mm & 2.41 & 3.0 \\
\hline
\end{tabular}


Table 3 test results after 07 hours of acid immersion

\begin{tabular}{|l|l|l|}
\hline Bitumen content & Control mix & PET mix \\
\hline Stability, kg & 451 & 1135 \\
\hline Flow value, $\mathrm{mm}$ & 2.51 & 2.89 \\
\hline
\end{tabular}

\section{Observations}

\section{1. observations from marshal stability test for control mix \& 6\% WPET mix after 3 hours of Acid immersion}

\subsubsection{Stability}

The maximum stability is exhibited by 6\% WPET mix I'e $1907 \mathrm{~kg}$, the control mix attains least stability of $1234 \mathrm{~kg}$ after 3 hours of acid immersion

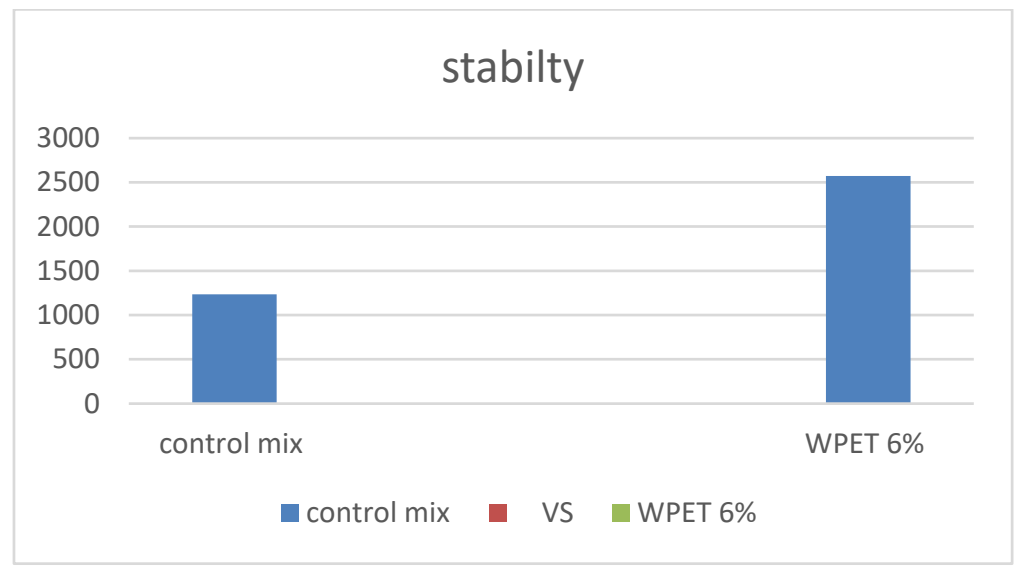

Figure 2 Comparison between stability results of control mix \& WPET 6\% after 3 hours of acid immersion.

\subsubsection{Flow}

The maximum flow value is attained by WPET $6 \%$ when as compared with control mix. The WPET $6 \%$ attains flow value of $3.3 \mathrm{~mm}$ \& control mix of $2.61 \mathrm{~mm}$.

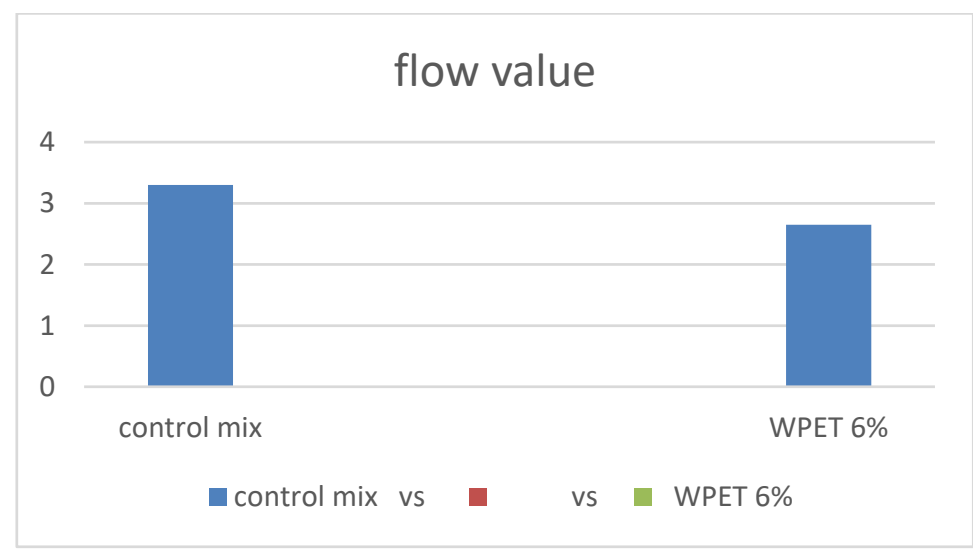

Figure 3 Comparison between flow value of control mix \& WPET 6\% after 03 hours of acid immersion 


\subsection{Observations from marshal test for control mix \& $6 \%$ WPET mix after 5 hours of acid immersion}

\subsubsection{Stability}

The maximum stability was found in WPET $6 \%$ mix of $17008 \mathrm{~kg}$ when compared with control mix whose stability was found to be $985 \mathrm{~kg}$.

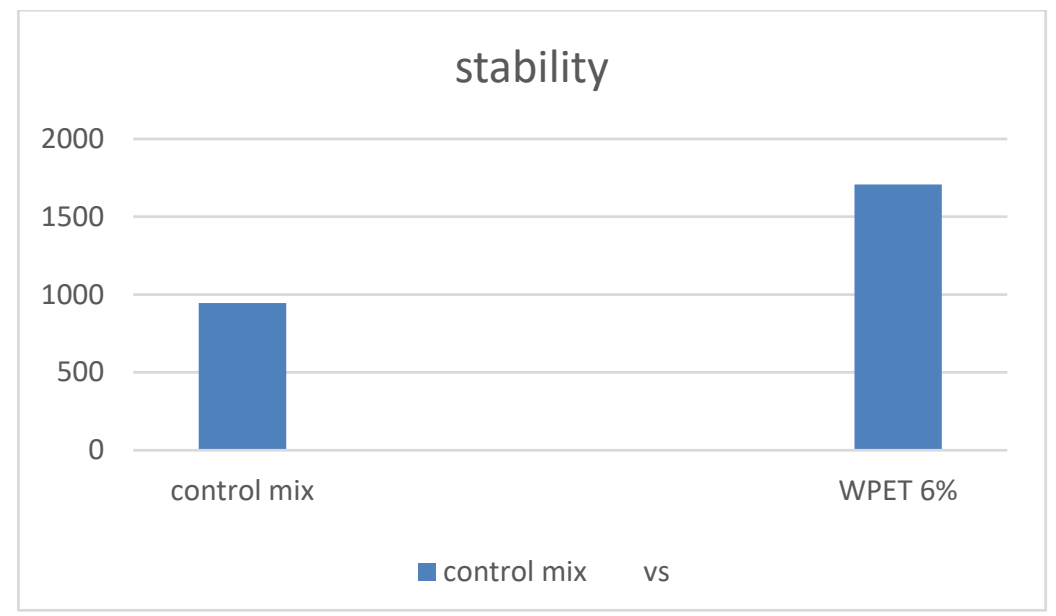

Figure 4 Comparison between stability of control mix \& WPET 6\% mix after 5 hours of acid immersion

\subsubsection{Flow value}

The maximum flow value is exhibited by WPET $6 \%$ mix of 3mm, control mix attains flow value of $2.41 \mathrm{~mm}$

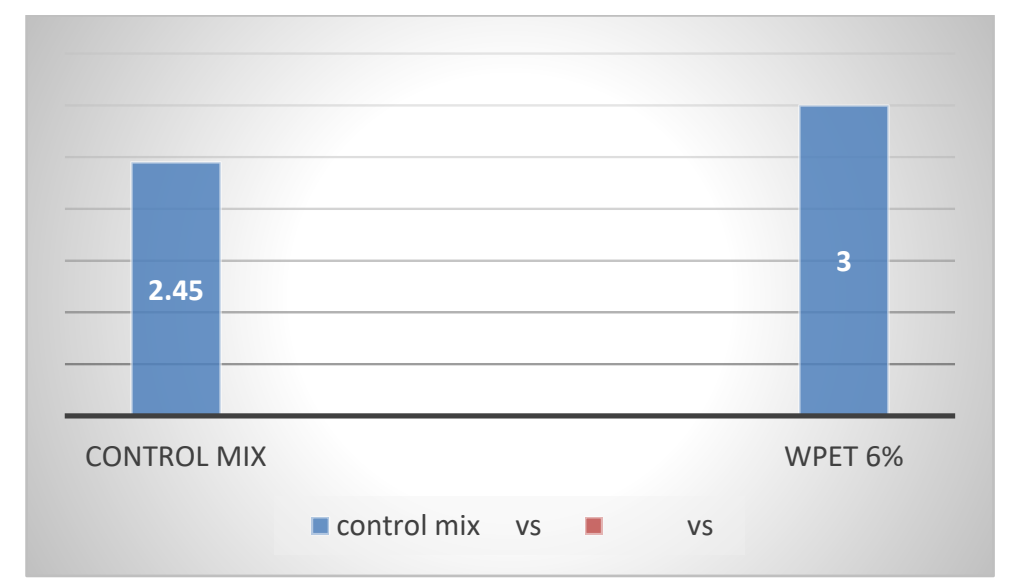

Figure 5 Comparison of flow value of control mix \& WPET 6\% mix after 5 hours of acid immersion

\subsection{Observations from marshal stability test for control mix \& $6 \%$ WPET mix after 7 hours of acid immersion}

\subsubsection{Stability}

The maximum stability is found in WPET 6\% mix when as compared with control mix. The WPET 6\% mix exhibits stability of $1135 \mathrm{~kg}$ and the control mix exhibits $451 \mathrm{~kg}$ of stability. 


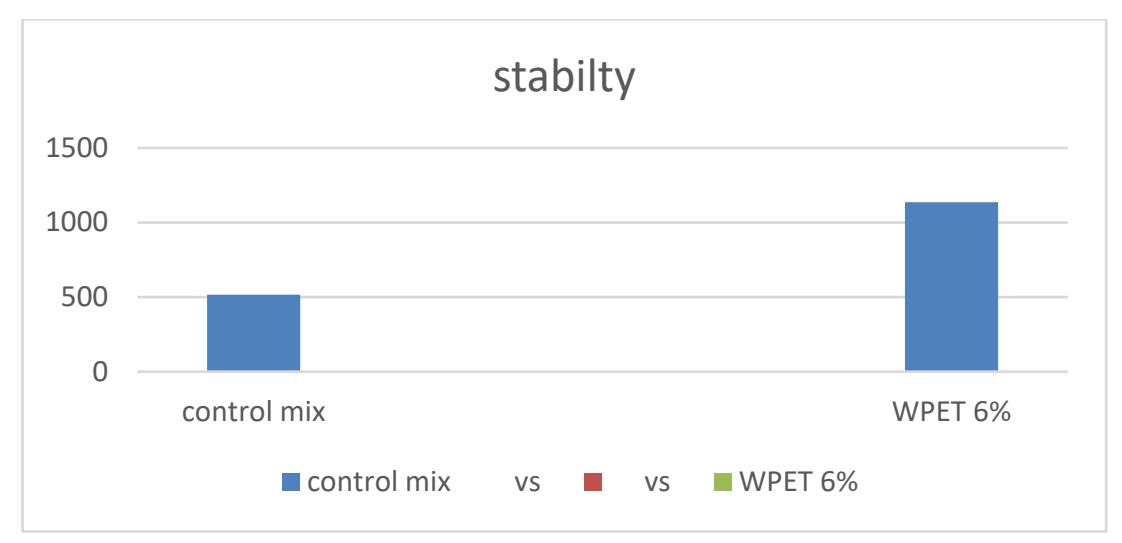

Figure 6 Comparison of stability between control mix \& WPET $6 \%$ after 07 hours of acid immersion

\subsubsection{Flow value}

The maximum flow value was exhibited by WPET $6 \%$ mix of $2.99 \mathrm{~mm}$, control mix attained flow value of $2.69 \mathrm{~mm}$

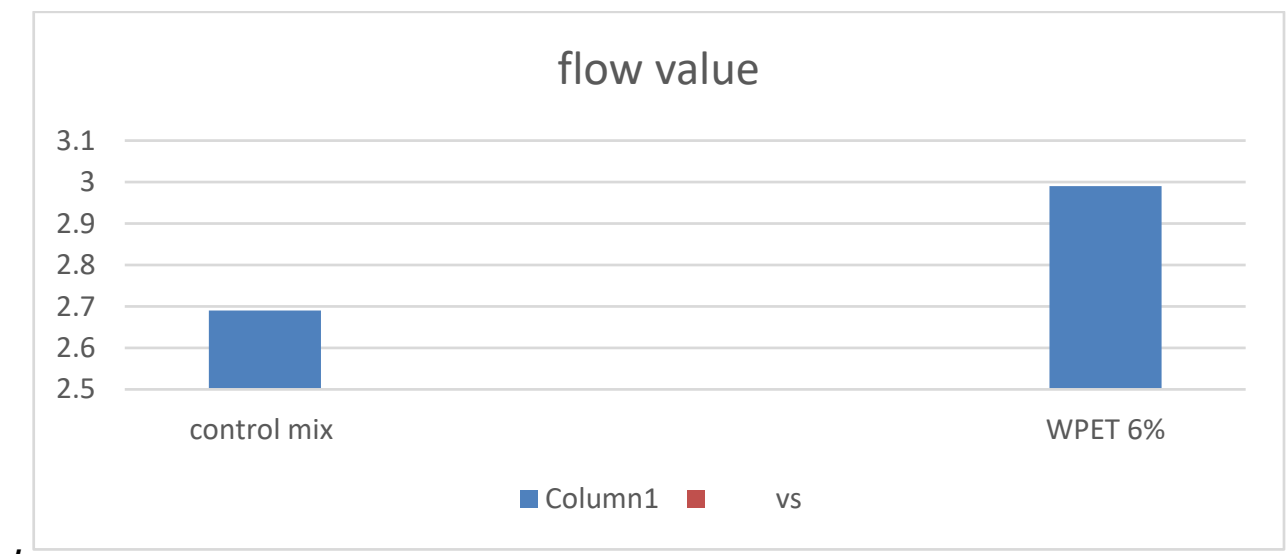

Figure 7 Comparison of flow value of control mix \& WPET 6\% mix after 07 hours of acid immersion

\section{Conclusion}

Under the effect of acid, samples with waste plastic shows excellent strength as compared to control mix After maximum 07 hours of acid immersion, WPET sample still exhibit's good strength of $1135 \mathrm{~kg}$ and control mix exhibit's least stability of $451 \mathrm{~kg}$ only from results \& observations, it can be concluded that use of waste plastic in bituminous surface course of Acid rain susceptible areas can be a good option.

Using waste plastics in construction of roads in acid rain prone areas can solve the degradation of pavements caused by the acid rain.

Also, by using waste plastic, roads constructed in such areas can prove to be economical.

\section{Compliance with ethical standards}

\section{Acknowledgment}

Thanks to Dr. Sanjay Sharma for proper review of our paper to increase clarity and scholar quality.

\section{Disclosure of conflict of interest}

The authors declare that there is no conflict of interest regarding the main research, authorship and publication of this paper. 


\section{References}

[1] Ahmadinia E, Zargar M, Karim M R, Abdelaziz M, "Performance evaluation of utilization of waste Polyethylene Terephthalate (PET) in stone mastic asphalt," Construction and Building Materials, 2012; vol. 36, pp. 984-989,.

[2] ASTM D6927-15, "Standard Test Method for Marshall Stability and Flow of Asphalt Mixtures," ASTM International, Pennsylvania.

[3] Awwad MT and Shbeeb L, "The use of polyethylene in hot asphalt mixtures," American Journal of Applied Sciences, 2007; volume 4, no. 6:pp. 390-396.

[4] Bindu CS and Beana K.S, "Influence of Additives on the Characteristics of Stone Matrix asphalt," International Journal of Resereach for Engineering Technology., 2014; vol. 3, no. 7:pp. 83- 88.

[5] Chavan M, "Use of Plastic Waste in Flexible Pavements," International Journal of Application or Innovation in Engineerring \& Technology, 2013; vol. 2, no. 4:pp. 540-552.

[6] Gawande A, Zamare G, RengeV C, Tayde S, and Bharsakale G, "An overview on waste plastic utilization in Asphalting of roads," Journal of Engineering Research and Studies, 2012; vol. III, no. II:pp. 1-5.

[7] Ghorpade M R “A Study of Enhancement of Bituminous Mix by Use of Modifiers,"Imperial Journal of Interdisciplinary Research, vol. 2018, no. 1, 2018.

[8] Gundaliya P J, "Utilization Of Waste Polyethylene Materials In Bituminous Concrete Mix For Improved Performance Of Flexible Pavements,"Indian Journal Of Applied Research September, 2012; Vol. 1Issue 12:pp. 2-3.

\section{Author's short biography}

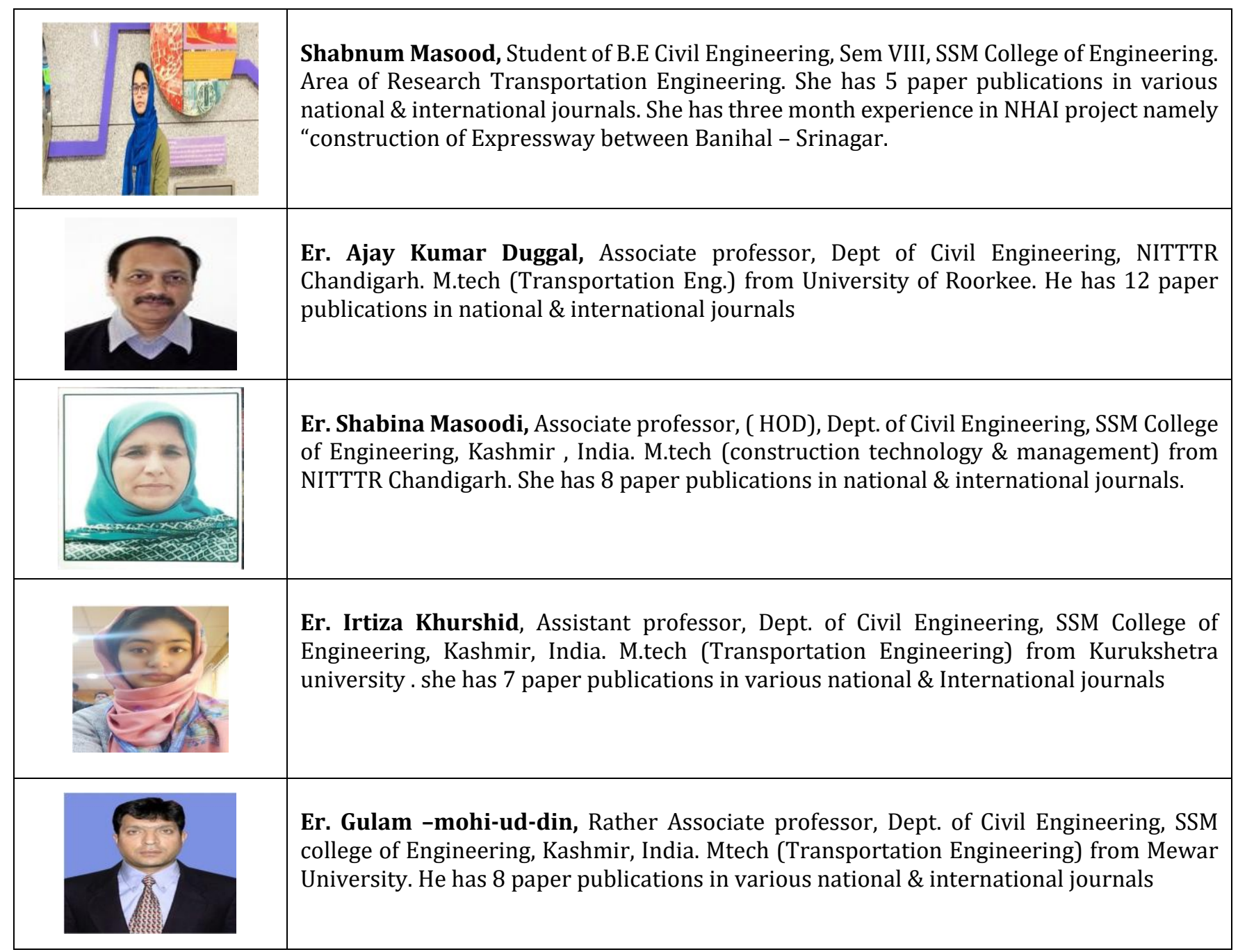

